\title{
Infectious mononucleosis in clinical practice
}

\author{
Aneliya Gotseva ${ }^{1}$, Vera llchova ${ }^{2}$, Emiliya \\ Badalanova $^{3}$
}

1. Laboratory of Virology, General Hospital "Uni Hospital";

2. Children's department, General Hospital "Uni Hospital";

3. Emergency department, General Hospital "Uni Hospital"

\begin{abstract}
Infectious mononucleosis (glandular fever) is a viral disease that occurs with tonsillitis and lymph node syndrome, together with characteristic changes in the hemogram. Laboratory confirmation of the diagnosis is most frequently performed by serological analysis aimed to detect specific IgM antibodies to the EBV capsid antigen (anti EBV VCA IgM). Not infrequently does it happen to not be identified on time in the clinical practice, which leads to the disease being diagnosed with delay usually after having conducted one or more antibiotic courses. The delay in diagnosis is most often attributed to the lack of consideration of a possible viral cause of tonsillitis in the differential diagnosis and the "blind" prescribing of antimicrobial therapy without carrying out routine laboratory tests (complete blood count, white blood cell differential count) and a throat swab culture.
\end{abstract}

Keywords: epstein-Barr virus, anti EBV VCA IgM, Enzyme Linked Fluorescent Assay. 


\section{Introduction}

In over $90 \%$ of cases, infectious mononucleosis (IM) is caused by Epstein-Barr virus (EBV, Human herpes virus 4) (8). EBV was discovered in 1964 by $M$. Epstein and $Y$. Barr, and it is the first herpes virus from which a viral genome was cloned. This virus targets the nasal and oropharyngeal epithelial cells and Blymphocytes (CD21 receptor)(4,11,12). EBV infection has two phases - lytic (replicative) and latent (persistent). After primary infection, EBV persists in the body lifelong in a latent state. However, reactivation may occur in certain conditions $(10,12)$. The response of T-lymphocytes is of the utmost importance for determining the clinical expression of EBV infection. After primary infection, the rapid and effective cellular response mediated by cytotoxic T-lymphocytes (CD8) and NK cells (Natural killers) causes lifelong suppression of the virus if the immune system is intact. Ineffective T-cell response can result in excessive and uncontrolled B-cell proliferation (5).

EBV is widespread in the human population. More than $90 \%$ of adults have serological evidence for prior infection with this virus (12). The main mechanism of transmission of infection is exposure to infected saliva from asymptomatic individuals (9). The incidence of infectious mononucleosis does not display a seasonal peak (7). Primary EBV infection occurs in childhood or young age, and is usually subclinical (4).Infectious mononucleosis is the most common clinical manifestation of primary infection with this virus in immunocompetent individuals, predominantly adolescents (6). The incubation period is 7-60 days (9). This disease may have a varied clinical presentations, but classic symptoms include the triad: fever, lymphadenopathy and sore throat $(4,12)$. Tonsillitis is a cardinal symptom, which is observed in over $90 \%$ of cases. In about $1 / 3$ of the patients, palatal petechiae are found in the posterior oropharynx (12). Enlargement of the cervical lymph nodes, especially those along the posterior margin of the sternocleidomastoid muscle, is typical. Lymphadenopathy is usually bilateral and symmetrical, and often generalized. Hepatomegaly with/without splenomegaly is often found. Liver involvement usually manifests as non-icteric hepatitis with mild to moderate elevations in serum transaminases. An early maculopapular rash on the body, which is transient and non-itchy, may develop, as opposed to drug-induced exanthem ("ampicillin rash"), which is itchy and prolonged. Changes in the hemogram are typical (12). Atypical lymphocytes with cytoplasmic plasmatisation and eccentric nuclei are detected by blood smear examination. In $80-90 \%$ of patients, lymphocytes are more than 50\% (9). In the past, non-specific assays for detection of heterophilic antibodies were used. Modern virological diagnostics is based on serological methods, blot analysis and molecular analysis (PCR). In routine laboratory practice, immunoassays (ELISA, ELFA) and chemiluminescent immunoassay (CLIA) are most widely used. During the lytic phase, EBV early antigens (EAs) and viral capsid antigens (VCAs) are produced, while in the latent phase, EBV nuclear antigens (EBNAs) are synthesized. Usually, the detection of specific EBV VCA IgM antibodies in the serum is sufficient for laboratory confirmation of the diagnosis. EBV VCA IgM antibodies are found in $75 \%$ of cases with acute infection $(2,10)$.

\section{Objective}

Two clinical cases of infectious mononucleosis are presented in order to focus on the clinical course of this disease, the typical laboratory abnormalities and the possibilities for serological confirmation of the 
diagnosis. The concomitant occurrence of tonsillitis, lymph node syndrome and febrile intoxication syndrome necessitates observing a viral cause in the differential diagnosis. The complex approach to the diagnostic process is considered essential by emphasizing on the good collaboration between the clinical and laboratory units.

\section{Material and methods}

During a three-year period (August 2016 - August 2019), 68 serum samples from outpatients and hospitalized patients were examined for EBV VCA IgM at the Virology Laboratory of Uni Hospital. We are presenting two clinical cases of serologically confirmed IM, which were diagnosed in March and August 2019. The diagnosis is based on the medical history, the objective clinical status and the laboratory tests. For the detection of specific anti-EBV VCA IgM antibodies in human serum samples, an automated VIDAS EBV VCA IgM (VCAM) assay based on state-of-the-art ELFA (Enzyme Linked Fluorescent Assay) technology, combining EIA with fluorescent assay, was used. Once the analysis was complete, the results were automatically analyzed by the computer.

\section{Case Description}

Patient No. 1 - K. Ts. D.-a boy at the age of 17 from the city of Sofia. The onset of the disease was at the end of March, with fever, sore throat and malaise. After examination by (a) general practitioner, purulent tonsillitis was diagnosed (Fig. 1) and an antibiotic (Augmentin) was prescribed. Due to the appearance of generalized maculopapular rash on the body (Fig. 2) and persistence of complaints, the patient was hospitalization-oriented for clarification of diagnosis.

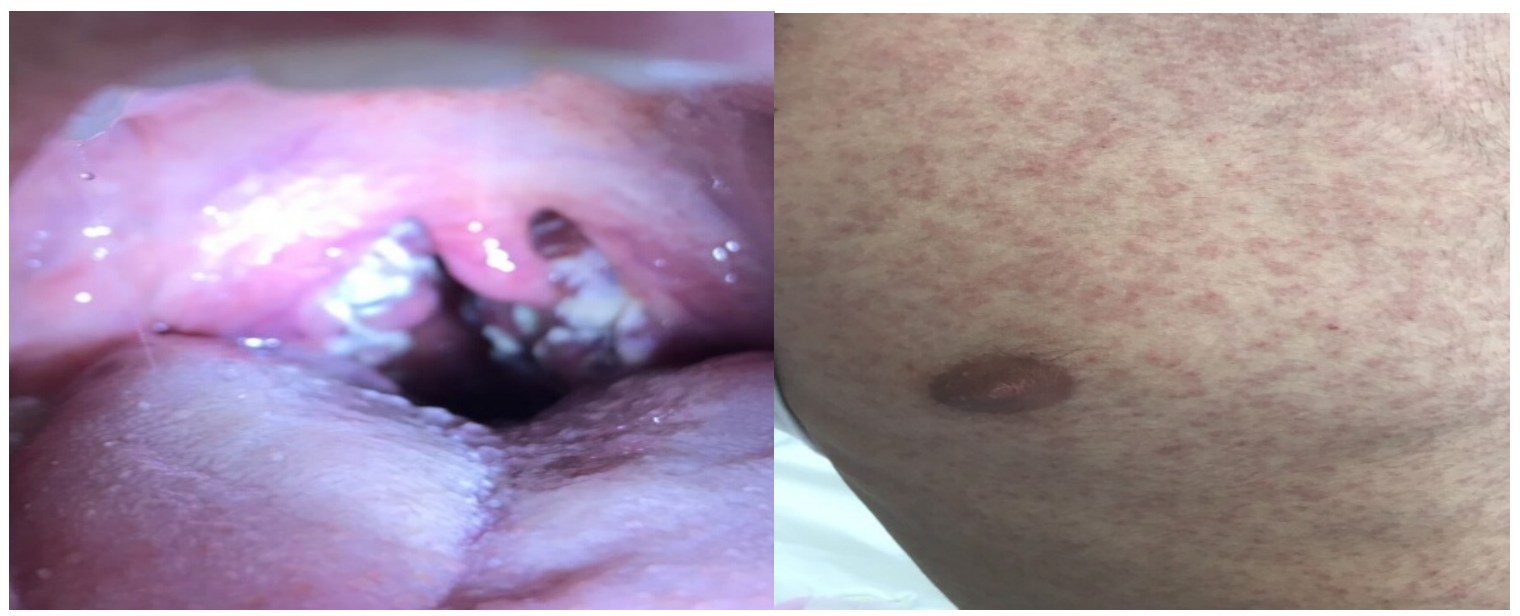

Fig. 1 Tonsillitis in IM (Patient No. 1).

Fig. 2 Drug-induced exanthem in IM 
Patient No. 2 - A. Ya.G- a girl at the age of 19 from the city of Panagyurishte. The onset of the disease was at the end of July, with sore throat, loss of appetite, malaise and nasal voice. During examination by (a) general practitioner, purulent deposits on the tonsils were found (Fig. 3). Antibiotic therapy with Augmentin was prescribed, which later was replaced with Klacid due to absence of response. On 03 August, the patient was examined at the emergency room of the hospital, infectious mononucleosis was observed and laboratory tests were performed: complete blood count + white blood cell differential count, liver enzymes, EBV serology (EBV VCA IgM/lgG).

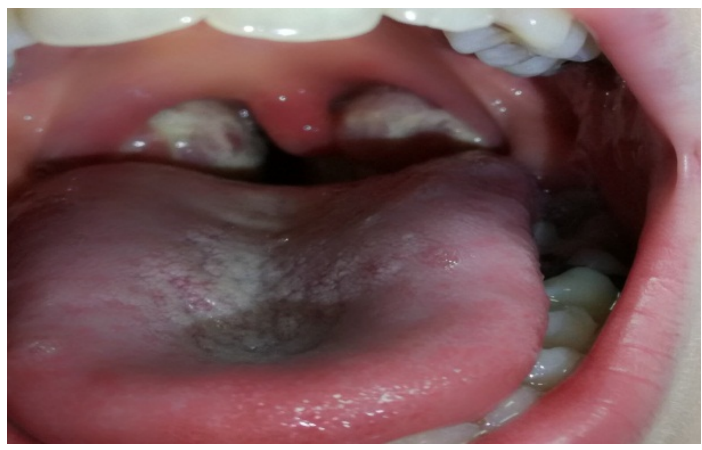

Fig. 3 Patient No. 2 - Tonsillitis in infectious mononucleosis

\section{Discussion}

68 serum samples from patients between the age of 1 and 22 were tested for EBV VCA IgM. Serologically confirmed cases of IM were 16 (16/68), of which 8 were in males and 8 in females. 52 patients (52/68) were negative. The major clinical presentations in the studied patients with IM were enlarged peripheral lymph nodes and inflammatory changes in the throat, in the absence of a suspected epidemiological history (history of contact with patients with similar complaints). The boy also had drug-induced maculopapular exanthem due to taking an antibiotic (Augmentin), as a result of transient penicillin hypersensitivity. Table 1 shows the laboratory parameters. In both patients, lymphocytosis was present, and moderate aminotransferase activity was found in patient No. 2. Similar results were obtained in a study conducted in Mexican children with IM, with lymphocytosis with atypical lymphocytes and elevated transaminases being the most common laboratory findings (8). 
Table 1 Paraclinic parameters of the two patients with infectious mononucleosis

\begin{tabular}{|l|l|c|c|}
\hline \multicolumn{1}{|c|}{ Lab. Tests } & Refference value & Patient № 1 & Patient № 2 \\
\hline Hemoglobin (HGB) & $120-180 \mathrm{G} / \mathrm{L}$ & $154 \mathrm{G} / \mathrm{L}$ & $125 \mathrm{G} / \mathrm{L}$ \\
\hline Leukocytes $(\mathrm{WBC})$ & $3.50-10.50 \mathrm{~g} / \mathrm{L}$ & $9.6 \mathrm{~g} / \mathrm{L}$ & $8.9 \mathrm{~g} / \mathrm{L}$ \\
\hline Lymphocytes (LYM) & $20-45 \%$ & $49 \%$ & $51 \%$ \\
\hline Monocytes (MONO) & $2-12 \%$ & $4.8 \mathrm{~g} / \mathrm{L}$ & $7.8 \%$ \\
\hline Thrombocytes (PLT) & $150-440 \mathrm{G} / \mathrm{L}$ & $212 \mathrm{G} / \mathrm{L}$ & $221 \mathrm{G} / \mathrm{L}$ \\
\hline AST (GOT) & $0-41 \mathrm{U} / \mathrm{L}$ & $24 \mathrm{U} / \mathrm{l}$ & $134 \mathrm{U} / \mathrm{l}$ \\
\hline ALT (GPT) & $0-42 \mathrm{U} / \mathrm{L}$ & $42 \mathrm{U} / \mathrm{l}$ & $426 \mathrm{U} / \mathrm{l}$ \\
\hline
\end{tabular}

In Bulgaria, infectious mononucleosis is not subject to mandatory registration, which is why there is no information on the incidence of this disease. A serious omission for timely diagnosis remains the lack of clinical focus and diagnostic approach in patients with tonsillitis and lymph node syndrome. The unnecessary prescription of antibiotics in the presence of pharyngitis without an etiological diagnosis is absolutely unjustified. Almási I. et al. (2001) proposed the introduction of a special protocol and regular monitoring of antibiotic administration in outpatient setting.(1).

\section{Conclusion}

Primary EBV infection in immunocompetent individuals in childhood and adolescence usually occurs asymptomatically, with seroconversion. Infectious mononucleosis is the most common clinical manifestation. The diagnosis is usually based on the clinical presentation of the disease and the laboratory test results. In certain cases, EBV hepatitis may develop, with mild to moderate elevations in liver enzymes (ALT, AST). Antibodies to the virus are detected in over $90 \%$ of the world population, regardless of sex and ethnicity. A major diagnostic serological marker for active EBV infection is the presence of EBV VCA IgM antibodies, which are highly sensitive and specific.

\section{References}

1. Almási I, Ternák G, Bali I. Clinical aspects of the diagnosis and treatment of infectious mononucleosis in primary care and in departments of infectious diseases. Orv Hetil. $2001 \mathrm{Apr}$ 29;142(17):899-903.

2. Balfour HH Jr, Odumade OA, Schmeling DO, Mullan BD, Ed JA, Knight JA, Vezina HE, Thomas W, Hogquist KA. Behavioral, virologic, and immunologic factors associated with acquisition and severity of primary Epstein-Barr virus infection in university students. J Infect Dis. 2013 Jan 1;207(1):80-8. doi: 10.1093/infdis/jis646. Epub 2012 Oct 24.

3. Balfour HH Jr, Dunmire SK, Hogquist KA. Infectious mononucleosis. Clin Transl Immunology. 2015 Feb 27;4(2):e33. doi: 10.1038/cti.2015.1. eCollection 2015 Feb. 
4. Cohen JI. Epstein-Barr virus infection. N Engl J Med. 2000 Aug 17;343(7):481-92.

5. Crawford DH. Biology and disease associations of Epstein-Barr virus. Philos Trans R Soc Lond B Biol Sci. 2001 Apr 29;356(1408):461-73.

6. Dunmire SK, Verghese PS, Balfour HH Jr. Primary Epstein-Barr virus infection. J Clin Virol. 2018 May;102:84-92. doi: 10.1016/j.jcv.2018.03.001. Epub 2018 Mar 5.

7. Ebell MH. Epstein-Barr virus infectious mononucleosis. Am Fam Physician. 2004 Oct 1;70(7):127987.

8. González Saldaña N, Monroy Colín VA, Piña Ruiz G, Juárez Olguín H. Clinical and laboratory characteristics of infectious mononucleosis by Epstein-Barr virus in Mexican children. BMC Res Notes. 2012 Jul 20;5:361. doi: 10.1186/1756-0500-5-361.

9. Gotseva A. Clinical characteristics of EBV infection. Medinfo.10/2013,31-33.

10. Lerner AM, Beqaj SH, Deeter RG, Fitzgerald JT. IgM serum antibodies to Epstein-Barr virus are uniquely present in a subset of patients with the chronic fatigue syndrome. In Vivo. 2004 MarApr;18(2):101-6.

11. Macsween KF, Crawford DH. Epstein-Barr virus-recent advances. Lancet Infect Dis. 2003 Mar;3(3):131-40.

12. Mandell, Bennett. Principles and Practice of infectious diseases. 6-th ed. Elsevier 2005- Part 3, 135:756-762.

\section{Corresponding author:}

Anelia Gotseva, Laboratory of Virology, General Hospital "Uni Hospital", email: anelialg@abv.bg 